Original Research Paper

\title{
Integrating an Imaging Session in Obstetrics and Gynaecology Curriculum as an Improvement in Undergraduate Medical Education
}

\author{
Kurien, A., Subramaniyam, V., Veasuvalingam, B., Goodson, $M$.
}

\begin{abstract}
Objective: Choosing the right modality of imaging and interpreting the results are challenging for undergraduate medical students as radiology remains underrepresented in the curriculum. An interdisciplinary workshop with integration of radiology in obstetrics and gynaecology was introduced and we analysed the student's perception of this novel approach.
\end{abstract}

Materials and methods: A mixed methodology was used. Data triangulation was done with questionnaire, written feedback, and peer observation. This workshop was conducted for final year medical students during their obstetrics and gynaecology rotation and the data was collected at the end of the session.

Results: A total of 122 students participated in the study. The results indicate an overall satisfaction rate of $98 \%$. Majority of the students (99\%) felt the material is clinically relevant and $97 \%$ reported gaining confidence in choosing the right imaging technique. The course organisation, presentation and knowledge levels were also rated very high. This was also evident in the narratives and peer observation.

Conclusion: The high satisfaction rate received for this innovation and integration supports conducting speciality-based radiology sessions. This can be viewed as a quality improvement technique to the undergraduate medical curriculum and will aid students for their future practice as safe foundation year doctors.

Key words: imaging, obstetrics and gynaecology, undergraduate medical curriculum, integration, student satisfaction.

\begin{abstract}
Introduction
Innovations in providing relevant and quality education to meet the changing needs of the patient care is a critical responsibility of all medical educators. Radiological investigations and image guided interventions have an integral part in the diagnosis and management of obstetrics and gynaecology conditions. There have been several advancements in the field of radiology which has rather grown exponentially in the last few decades. Advancements in imaging technology have significantly improved gynaecological and obstetric practice over the years (WinerMuram1999; Harrison et al. 2003; Freeman et al. 2009). Ultrasound is like an extension of clinician's hands in obstetrics and gynaecology and together with other imaging modalities constitute a powerful teaching aid. This should be reflected in the undergraduate curriculum to ensure up to date learning opportunities with
\end{abstract}

Newcastle University Medicine Malaysia

Corresponding author::Alice Kurien,

Alice.Kurien@newcastle.edu.my appropriate knowledge and skills essential for meeting the requirements for future practice. However, in many medical schools currently available modules have not kept the pace to incorporate these advancements in medical imaging in the undergraduate curriculum (Ozuah 2002; Nyhsen et al. 2013; Mirsadraee et al. 2017). More studies are required for standardization of the radiology curriculum for undergraduates (Kourdioukova et al. 2011).

The representation of radiologists in planning and teaching the undergraduate curriculum is an essential requirement to provide a more standardized education (Straus et al. 2014; European Society of Radiology [ESR] 2018). Integration is the best way to improve this. Fortunately, most universities have moved from the traditional independent courses to an integrated learning (Pasquale \& Krane 2014). Newcastle University Medicine Malaysia is the international branch campus of Newcastle University UK. Though ours is an integrated curriculum, the integration of radiology is not uniformly focussed on different specialities and hence the undergraduate medical students 
have limited formal learning opportunities in diagnostic radiology in obstetrics and gynaecology. The students often struggle in choosing the right modality of imaging technique and interpreting the results in obstetrics and gynaecology conditions.

Exploring the student satisfaction in an academic program would identify the strengths, weaknesses and facilitate providing better services to students. In higher education, learners voice has more value than ever before, and it should also be used as a guide for designing teaching and shaping their educational experience.

We introduced an integrated imaging session in the existing program as an innovation to improve the current curriculum by enhancing students' ability to choose basic imaging investigations in the specialty, write radiology request form and interpret the results. We conducted a survey after this new teaching session.

\section{Objectives}

The aim of the study was to examine the student satisfaction and their perception of the effectiveness of this novel integrated approach as a learning opportunity. The research questions that informed the study were

1. Does the imaging in obstetrics and gynaecology workshop enable students to achieve the intended learning outcomes?

2. What are the perceived learning experiences of the participants after attending the workshop?

Practice Points:

1. Imaging is an integral part of diagnosis and management of Obstetrics and Gynaecology conditions.

2. Radiology is under-represented in the undergraduate curriculum of many universities and every effort to promote the advancements in radiology and patient care pathway is crucial as a quality improvement program in undergraduate curriculum.

3. Integrated sessions would provide a clear understanding of the role of radiology in patient care and improved clinical experience.

4. Systems for evaluation of any innovation in education would facilitate future planning, selfreflection and adding student voices in their learning.

\section{Materials \& Methods}

\section{Ethical Clearance:}

Approval for the research was obtained from the research management group of NUMed Malaysia and ethics committee Newcastle University UK. Participants were explained about the purpose of the research, data collection process and confidentiality. It was optional to participate in the study.

\section{Study Setting \& Sample Selection}

\section{Study Setting:}

Novel Integrated Radiology- Obstetrics and Gynaecology Workshop

The interdisciplinary radiology workshops were conducted for the final year medical students during their obstetrics and gynaecology rotations in Newcastle University Medicine (NUMed) Malaysia during the year 2018-19. Five such workshops were conducted, one for each rotation. Specialists from obstetrics and gynaecology and the radiologist together conducted the sessions. One of our colleagues with no connection to this study was recruited to be a peer observer and submitted the comments at the end of the session. The learning objectives were carefully developed based on the standards recommended for the undergraduates and this was clearly explained to the students.

The half day workshops progressed through different levels of learning such as interactive lectures on indications and limitations of obstetrics and gynaecology imaging, quiz using an anonymous voting system with OMBEA response system, problem-based discussion, radiology request writing exercise and the communication skills required for explaining the procedures and results of imaging.

Ultrasound scanning is the imaging of choice as a first line in women's health conditions. Use of ultrasound in normal and high-risk pregnancies, screening for foetal abnormalities, pelvic ultrasound imaging in pelvic pain, other modalities of imaging in gynae oncology and in other gynaecological problems were included in the workshop. Special emphasis was given for the safety issues and cost effectiveness of different modalities of imaging. Relevant resources were also provided to reinforce further learning. 
Sample Selection:

A convenience purposive sampling was used in this study (Guba, 1994). All stage 5 students who attended the sessions were recruited after consent. A total of 122 students participated voluntarily. A total of 5 peer observer comments were acquired, one for each session. Data gathering took place between October 2018 and February 2019.

Quantitative data collection was done with a 15stem questionnaire. This was purposefully designed by us and validated for this study. The statistical analysis also showed a high degree of reliability (Cronbach's alpha of 0.882 ). The 15 questions addressed the student's perception and were grouped under different aspects of their learning on a five-point Likert scale. Organization, knowledge, relevance of the topics, instructor satisfaction, motivation, and confidence were the main domains assessed in the questionnaire. Students completed this questionnaire after the session was over and was done by the peer colleague to give them the freedom of expression.

Qualitative data was collected from the written feedback and from the comments of the peer observer. All these data were stored confidentially according to the recommendations from the committee and following the general principles of data protection.

Data Analysis

Quantitative analysis:

Statistical analysis was carried out for the questionnaire survey using the statistical software IBM SPSS Statistics for Windows
(SPSS Version 24.0. Armonk, NY: IBM). Graphical calculations and percentages were calculated.

Qualitative Analysis:

Given the thought of Post positivism, Thematic analysis was carried out using the Braun and Clarke six phase framework (Figure 2) was applied for the free text comments and peer observation remarks (Braun \& Clarke, 2006). This includes organizing and identifying patterns from the data sample after coding of the initial raw data. This gives the flexibility to work with diversity, an added advantage in a study which looks at students' perception as in here (Maguire, 2017). A sample of free text comments and coding and themes generation is showed in figure 3 .

\section{Results}

The integrated workshop on imaging in obstetrics and gynaecology was introduced in the curriculum and the study draws on undergraduate medical students' experience on this innovation. Findings of this study show the usefulness of the session and fulfilment of their expectations.

The survey response rate was $89.70 \%$ $(n=122)$. Respondents' opinion (As shown in Figure 1) indicates an overall student satisfaction rate of $98 \%$. Majority of our students, $99 \%$ felt the content of the materials is clinically relevant and they received appropriate resources for learning. For the course organisation there was $95 \%$ agreement

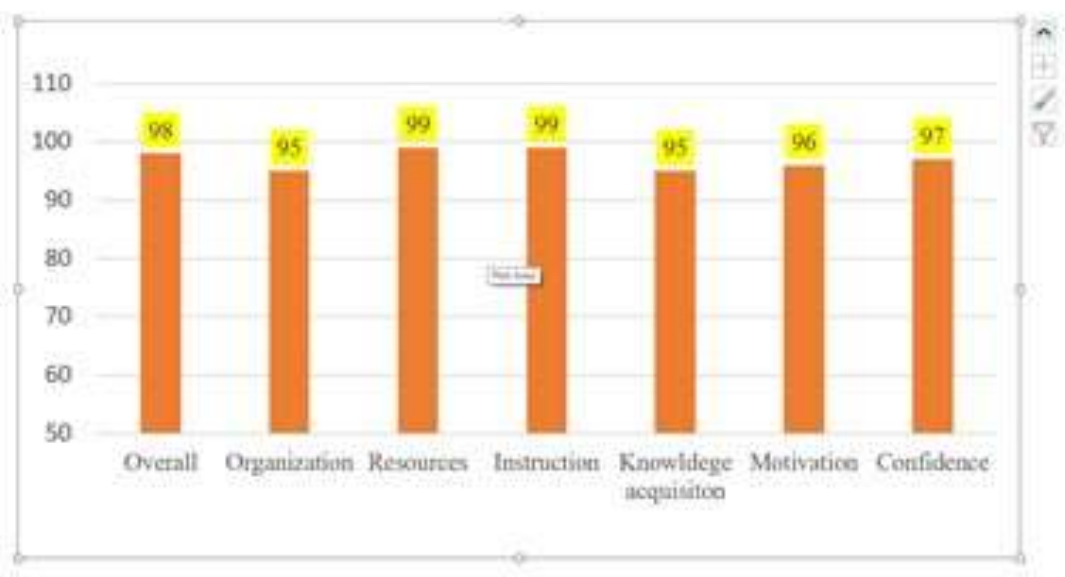

Figure 1. The percentage of satisfaction across various stems in the

questionnaire. 
Steps of Thematic Analysis

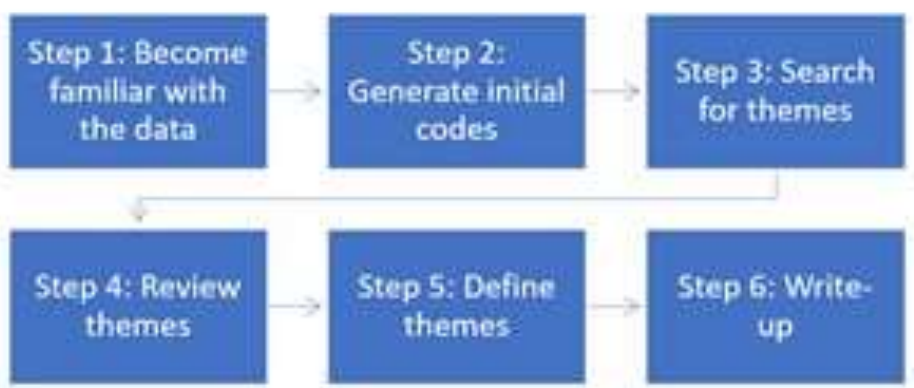

Figure 2. The steps of thematic analysis following the Braun and Clarke

Framework.

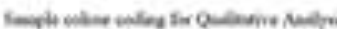

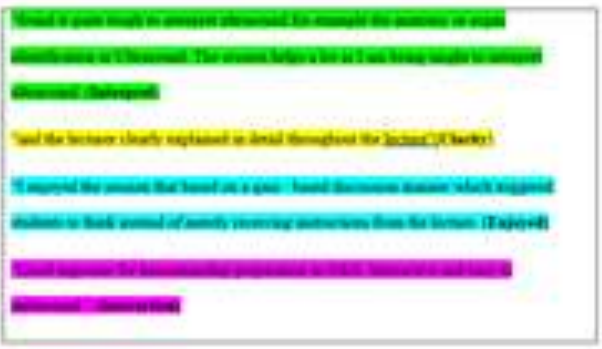

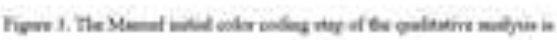

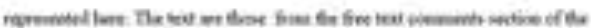

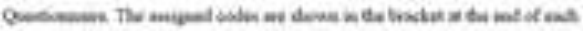

with satisfaction. A similar percentage of student satisfaction was received for knowledge acquisition. Instructional quality received a high rating of $99 \%$ satisfaction. Also, 97\% respondents agreed that they gained confidence in choosing the right imaging technique. Motivation to learn further on the subject were reported by $96 \%$ of our students and they recommended similar sessions for future batches.

The four themes that emerged from the Qualitative Analysis were Interpretation, Knowledge gained, Interesting and Critical thinking (Figure 4).
Interpretation:

One of the factors that had a particularly positive influence on the student satisfaction was that the perceived benefit of the session in their confidence level and achieving the intended learning outcomes. Some of their comments were as following.

"I get to know about what imaging to use for what conditions. To learn to choose the most appropriate imaging modality for the relevant obs and gyn problem".

"This is very useful for my MOSLER examination and the final year exam".

"This session helps a lot as I am being taught to interpret ultrasound". 


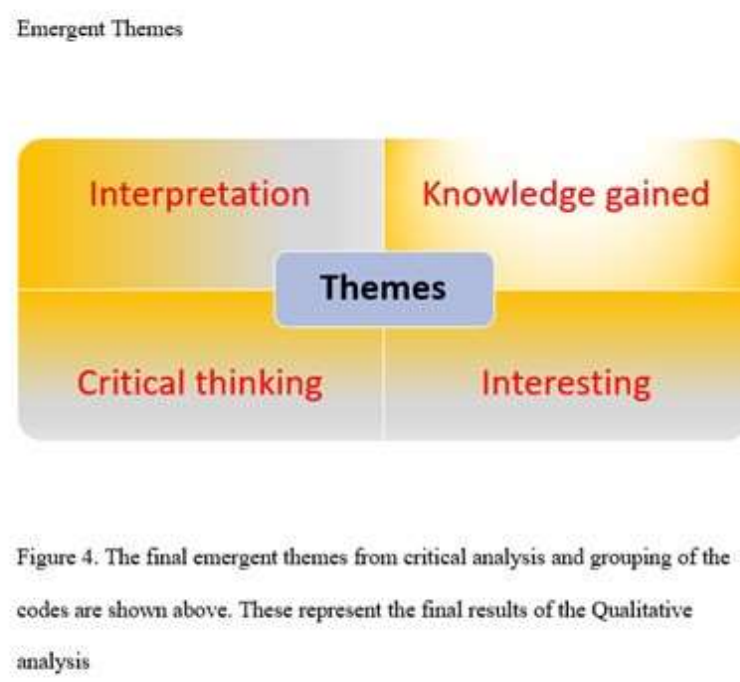

Knowledge Acquisition:

Knowledge can be achieved by different approaches but when it is guided by experts to apply that knowledge it is more effective. Quiz helped to gauge the prior knowledge of the students and channel the discussions following that to enable students to clear their misconceptions. Students appreciated the extra knowledge they gained and $95 \%$ of our students agreed that the course enabled them to receive the desired knowledge.

Interesting:

All students (100\%) attended the session. Motivation, a desire to learn is a powerful factor in learning and $96 \%$ felt that they want to have more sessions like this in future and recommended to continue this for future batches. Some of them were eager to have extra practice material. Their narratives included:

"It is recommended for radiology topics to be included in regular teaching schedules not only for obstetrics and gynaecology but also in other specialities".

"There were SBA'S. Q/A session - stimulate thinking. Could have more SBA in radio imaging in future".

"May be even prepare some questions on paper for students to do back at home so that they can refreshed on what was learnt during the session".

Students appreciated the integration and interactions which made the session "interesting", which was one of the themes emerged from the narratives. "I like the way of delivering the of teaching. Image and question and then followed by clear explanation".
Critical thinking:

Exploring areas of improvement, involving new disciplines based on medical field advancements, implementing, and sharing common resources are increasingly important to customize the model to various institutions. It aids our undergraduates with the necessary capabilities for future practice. This new design achieved the goal and was shared with other base units aiming for a community of practice in improving the curriculum.

\section{Discussion}

The integrated workshop on imaging in obstetrics and gynaecology was introduced in the curriculum and the study draws on undergraduate medical students' experience on this innovation. Findings of this study show the usefulness of the session and fulfilment of their expectations.

Student's expectations are growing, and institutions are increasingly accountable for student satisfaction. Students satisfaction is a key factor in determining such quality of education. Student satisfaction is a multidimensional psychological process (Weerasinghe, Lalitha \& Fernando 2017) and student satisfaction survey is a valuable tool to assess their perception on the quality of teaching and learning experience. Introducing a culture of incorporating student voice in their education is the key to innovative solutions in higher education (Mac Cracken 2018). We conducted a joint workshop with radiologist during women's health rotation and supported it with extra resources. 
The choice of final year medical students for this intervention was determined by the student feedback and the importance of confidence and competencies required for the transition of medical students to doctors. A considerable number of international surveys have recommended proposals for curricular reform for integrating radiology in medical education (Straus et al. 2014 \& Royal College of Radiologists [RCR] 2017). Exploring new options to meet these requirements is the key to optimise learning experience in the evolving medical field. Integrating radiology into the existing curriculum, finding new tools such as elearning, flipped classroom, problem- based learning and computer programs for simulation are recommended approaches to achieve quality education and improved diagnostic reasoning (ESR, 2019).

The expert consensus survey conducted in UK (Mirsadraee, 2012) provides highly useful directives for incorporating radiology in undergraduate curriculum. The topics were selected based on student feedback and incorporating the recommendations from various regulatory and professional bodies setting the standards for medical education (Royal college of Obstetricians and gynaecologists [RCOG] 2009 \& RCR 2017). "A newly qualified doctor should be able to interpret the results of investigations and diagnostic procedures, in collaboration with colleagues if necessary" General Medical Council [GMC] (2018).

Clinical environment would be the best place to learn about the cases, but the opportunities are limited for the students to directly observe the decision making on the investigation reports or procedures such as transvaginal ultrasound. How an extra learning opportunity could be incorporated into the existing teaching in the current curriculum without disrupting the time allotted for other learning objectives was discussed in the annual quality meeting and with the radiologist. Introducing the integrated session in the existing programme was chosen as it would not affect the time allotted for other compulsory sessions.

Innovations are challenging but if supported by research is an avenue of communication that would help to identify the quality of the teaching undertaken and to make any amendments for future use. Evidenced based analysis of the strengths and weaknesses is integral as an indicator of the success of the intervention (Tavakol \& Sandars, 2014). Our study clearly indicates a successful integration and several benefits of this innovation from the student perspective and peer observation point of view. The themes emerged from the narratives complemented the results of quantitative analysis. Students were asked to give their overall satisfaction of the session. The overall student satisfaction in this study was $98 \%$ supporting the positive experiences students had in their learning. Overall satisfaction is an initial response because of general level of satisfaction, and it is based on several factors such as the course content, duration, relevance, interactions etc. Overall satisfaction could reflect increased understanding of the topics, engagement in the class and is a valuable tool for future planning. This could also promote a positive attitude towards the speciality radiology for their future training. In the questionnaire overall satisfaction is just one question but the rating for other individual questions and the themes emerged from the narratives reinforces the rating for overall satisfaction. Among the variables of student satisfaction, maximum satisfaction was with quality of instruction and resources. Bell and Brooks (2017) identified teaching and course organization as the most relevant subareas of student satisfaction in UK's national student survey.

The quality of teaching and learning experience is more important than any other facilities during the academic life of students and universities should adapt the services offered focussing on the results of this pertinent aspect in their satisfaction surveys (Douglas et al 2006). Quality of instruction is vital in student engagement and motivation in higher education (Sogunro, 2017; Butt \& Rehman 2010). Our students' perceived satisfaction on the quality of instruction is rated as $99 \%$ satisfaction. Many positive comments were highlighted in their narratives. Students were encouraged "to think instead of merely receiving instructions from the lecturer". They also expressed that learning session contributed to a "good exposure for housemanship preparation in O\&G" and was "interactive and easy to understand."

Our findings also show that there was 99\% satisfaction with the teaching materials (resources) we used for this session. Academic resource available for the learning is one of the key determinants of student satisfaction. The learning outcomes were clearly described, and we used different methods to engage the students in a highly interactive way. In the free text comment also, this is evident as students regards "the study materials prepared were well 
arranged with appropriate and timely practical sessions.

Limitation

One of the limitations faced in this workshop was bringing real patients to the workshop. Students are encouraged to utilize any opportunity to observe the procedure in the clinical setting and review the imaging reports. This research is the first study for this innovation. As this is an internal evaluation and conducted only in one discipline it could be argued that the results may not be generalisable.

\section{Conclusion}

The integrated obstetrics and gynaecology imaging workshop provided a significant opportunity for our students to learn from the collaboration of academics and understand the explicit role of radiology in women's health conditions. The workshop covered the core competencies in women's health imaging required for a foundation doctor. In the light of high-level student satisfaction evidenced by both qualitative and quantitative results, we are in favour of continuing this innovation for the future batches. Listening to students' voice, establishing partnership with various disciplines, curriculum innovation and evaluating student experience are made use of as quality improvement program. More integration, coordination as an agreed curriculum in the future and further research would provide better insight to student experience and aid in identifying areas that needs improvement.

\section{Conflicts of Interest}

None

\section{References}

Bell, AR., Brooks, C., (2017). What makes students satisfied? A discussion and analysis of the UK's national student survey [online].42(8)1118-1142. [Viewed 17 June 2020]. Available from: https://www.tandfonline.com/doi/pdf/10.1080/03 09877X.2017.1349886

Braun, V., Clarke, V., (2006). Using thematic analysis in psychology. Qualitative Research in Psychology [online].3(2):77-101. [Viewed 23 May 2020]. Available from: https://www.researchgate.net/publication/23535639

3_Using_thematic_analysis_in_psychology

Butt, BZ., ur Rehman, K., (2010). A study examining the students' satisfaction in higher education. Procedia - Social and Behavioral Sciences [online].5446-5450. [Viewed 10 June 2020]. Available from: https://www.researchgate.net/publication/24860 $\underline{7365}$

Douglas, J., Douglas, A., Barnes, B., (2006). Measuring student satisfaction at a UK university. Quality Assurance in Education [online]. [Viewed 16 June 2020]. Available from: https://www.researchgate.net/publication/24234 $\underline{9098}$

European Society of Radiology [ESR], (2017). Undergraduate education in radiology. [online]. [Viewed 16 May 2020]. Available from:

https://www.myesr.org/education/undergraduateeducation-radiology

European Society of Radiology [ESR], (2019). Statement on new approaches to undergraduate teaching in Radiology [online]. [Viewed 29 May 2020]. Available from:

https://insightsimaging.springeropen.com/article s/10.1186/s13244-019-0804-9\#citeas

Freeman, S., Hampson, F., Addley, H., Moyle, P., Sala, E., (2009). Imaging of the female pelvis. Obstetrics, Gynaecology and Reproductive Medicine [online].19(10):271-281. [Viewed 4 August 2020]. Available from: doi:10.1016/S0733-8627(03)00047-6

General Medical Council [GMC], (2018). Outcomes for graduates [online]. [Viewed 29 May 2020]. Available from:

https://www.gmc-uk.org//media/documents/dc11326-outcomes-forgraduates-2018 pdf-75040796.pdf

Guba, EG. and Lincoln, YS., (1994). Competing paradigms in qualitative research. In: NK. Denzin and YS. Lincoln, eds. Handbook of qualitative research. CA: Sage; pp.105-117.

Harrison, BP., Crystal, CS., (2003). Imaging modalities in obstetrics and gynaecology. Emerg Med Clin North Am [online].21(3)711-35. [Viewed 3 August 2020].Available from: https://doi:10.1016/j.ogrm.2009.06.004

MacCracken, A., (2018). Student Voice: The Ultimate Higher Education Innovation? Higher learning advocates. [Viewed 3 June 2020]. Available from: https://higherlearningadvocates.org/2018/09/27/ student-voice-the-ultimate-higher-educationinnovation/ 
Maguire, M., Delahunt. B., (2017). Doing a thematic analysis: A practical, step-by-step guide for learning and teaching scholars. All Ireland Journal of Higher Education, [online].9(3). [Viewed 2 June 2020]. Available from: https://www.clinicalradiologyonline.net/article/S0 009-9260(12)00160-2/fulltext\#tbl2

Mirsadraee, S., Mankad, K., McCoubrey, P., Roberts, T., Kessel, D, (2012). Radiology curriculum for undergraduate medical studies. A consensus survey. Clinical radiology. [online].67(12),1155-1161. [Viewed 23 May 2020]. Available from: doi: 10.1016/j.crad.2012.03.017

Nyhsen CM, Steinberg LJ, O'Connell, JE., (2013). Undergraduate radiology teaching from the student's perspective. Insights into Imaging [online]. 4,103-109. [Viewed 23May 2020]. Available from: https://doi.org/10.1007/s13244012-0206-8

Oris, EV., Valcke, M., Derese, A., Versreate, KL., Analysis of radiology education in undergraduate medical doctors training in Europe [online]. 78(3):309-318. [Viewed 23 May 2020]. Available from: doi: 10.1016/j.ejrad.2010.08.026

Ozuah, PO., (2002). Undergraduate medical education: Thoughts on future challenges BMC Medical Education [online]. 2(8). [Viewed 23 May 2020]. Available from: https://doi.org/10.1186/1472-6920-2-8

Pasquale, SJ. and Krane, NK. (2014). Designing a course. In: K. Huggett and WB. Jeffries, eds. An Introduction to Medical teaching. $2^{\text {nd }}$ ed. USA: Springer; pp161-172.

Royal College of Radiologists [RCR]., (2017). Undergraduate radiology curriculum, second edition [online]. [Viewed 3 June 2020]. Available from:

https://www.rcr.ac.uk/sites/default/files/documen ts/undergraduate radiology curriculum second edition 2017.pdf
Sogunro, OA., (2017). Quality Instruction as a Motivating Factor in Higher Education. International Journal of Higher Education [online].6 (4) 173- 184. [Viewed 8 June 2020]. Available from: http://ijhe.sciedupress.com

Straus, C., Webb. EM., Kondo, KL., Phillips, AW., Naeger, DM., Carrico, CW., Herring, W., Neutze, JA., Haines, GR., Dodd, GD., (2014). Medical Student Radiology Education: Summary and Recommendations from a National Survey of Medical School and Radiology Department Leadership. J Am Coll Radiol [online].11(6):60610. [Viewed 16 May 2020] Available from: doi: 10.1016/j.jacr.2014.01.012

Tavakol, M., Sandars, J., (2014). Quantitative and qualitative methods in medical education research: AMEE Guide No 90: Part II. Medical Teacher [online].36:10, 838-848. [Viewed 10 August 2020]. Available from: https://doi.org/10.3109/0142159X.2014.915297.

Weerasinghe, S., Lalitha, S., Fernando, RLs., (2017). Students' Satisfaction in Higher Education Literature Review. American Journal of Educational Research [online]. 5(5), 533-539. [Viewed 10 June 2020].Available from https://www.researchgate.net/publication/32502 $\underline{2530}$

Winer-Muram, H., (1999). Diagnostic imaging in obstetrics and gynecology: new developments. Curr Opin Obstet Gynecol [online].11(5) 421-5. [Viewed 4 August 2020]. Available from: doi: 10.1097/00001703-199910000-00002 